\title{
Stress induced Salmonella Typhimurium recrudescence in pigs coincides with cortisol induced increased intracellular proliferation in macrophages
}

Elin Verbrugghe ${ }^{1 *}$, Filip Boyen ${ }^{1}$, Alexander Van Parys ${ }^{1}$, Kim Van Deun $^{1}$, Siska Croubels ${ }^{2}$, Arthur Thompson ${ }^{3}$, Neil Shearer ${ }^{3}$, Bregje Leyman ${ }^{1}$, Freddy Haesebrouck' ${ }^{1}$ and Frank Pasmans ${ }^{1}$

\begin{abstract}
Salmonella Typhimurium infections in pigs often result in the development of carriers that intermittently excrete Salmonella in very low numbers. During periods of stress, for example transport to the slaughterhouse, recrudescence of Salmonella may occur, but the mechanism of this stress related recrudescence is poorly understood. Therefore, the aim of the present study was to determine the role of the stress hormone cortisol in Salmonella recrudescence by pigs. We showed that a $24 \mathrm{~h}$ feed withdrawal increases the intestinal Salmonella Typhimurium load in pigs, which is correlated with increased serum cortisol levels. A second in vivo trial demonstrated that stress related recrudescence of Salmonella Typhimurium in pigs can be induced by intramuscular injection of dexamethasone. Furthermore, we found that cortisol, but not epinephrine, norepinephrine and dopamine, promotes intracellular proliferation of Salmonella Typhimurium in primary porcine alveolar macrophages, but not in intestinal epithelial cells and a transformed cell line of porcine alveolar macrophages. A microarray based transcriptomic analysis revealed that cortisol did not directly affect the growth or the gene expression or Salmonella Typhimurium in a rich medium, which implies that the enhanced intracellular proliferation of the bacterium is probably caused by an indirect effect through the cell. These results highlight the role of cortisol in the recrudescence of Salmonella Typhimurium by pigs and they provide new evidence for the role of microbial endocrinology in host-pathogen interactions.
\end{abstract}

\section{Introduction}

For a long time it has been known that stress may cause recrudescence of some bacterial infections in food-producing animals, such as poultry and pigs [1,2]. Salmonellosis is one of the most important zoonotic bacterial diseases and pigs are considered as one of the main sources of human salmonellosis [3-6]. Worldwide, Salmonella enterica subspecies enterica serovar Typhimurium (Salmonella Typhimurium) is the predominant serovar isolated from slaughter pigs [7]. Pigs infected with Salmonella Typhimurium can carry this bacterium asymptomatically in their tonsils, gut and gut-associated

\footnotetext{
* Correspondence: Elin.verbrugghe@ugent.be

'Department of Pathology, Bacteriology and Avian Diseases, Faculty of Veterinary Medicine, Ghent University, Salisburylaan 133, 9820 Merelbeke, Belgium

Full list of author information is available at the end of the article
}

lymphoid tissue for months resulting in so called Salmonella carriers. Generally, these persistently infected animals intermittently shed low numbers of Salmonella bacteria. However, during periods of stress, like transport to the slaughter house, recrudescence of Salmonella may occur. This results in increased crosscontamination during transport and lairage and to a higher degree of carcass contamination, which could lead to higher numbers of foodborne Salmonella infections in humans $[4,8]$. Until now, the mechanism of stress related recrudescence of Salmonella is not well understood and this study aimed at elucidating this phenomenon.

Although stress is hard to define and the factors causing stress can be very different, they generally result in similar physiological responses. A period of stress results

\section{Ciomed Central}


in the release of a variety of neurotransmitters, peptides, cytokines, hormones, and other factors into the circulation or tissues of the stressed organism [9-11]. Besides the fast-acting catecholamines, which are released by the sympathetic nervous system, the hypothalamic-pituitaryadrenal axis becomes activated, resulting in the release of the slow-acting glucocorticoids by the adrenal gland [12]. These stress hormones can not only affect the host immune response via the modulation of various aspects of the immune system, but they also can have a direct effect on the bacteria and may influence their interactions with the host cells [13]. Indeed, several bacterial species can exploit the neuroendocrine alteration of a host stress reaction as a signal for growth and pathogenic processes $[12,14,15]$.

Pigs secrete cortisol as the predominant glucocorticoid [16]. Therefore, it was the aim of the present study to determine the role of this hormone in the stress related recrudescence of Salmonella Typhimurium by pigs and to elucidate if it alters bacterium-host cell interactions.

\section{Materials and methods Chemicals}

Cortisol and dexamethasone (Sigma-Aldrich, Steinheim, Germany) stock solutions of $10 \mathrm{mM}$ were prepared in water and stored at $-20^{\circ} \mathrm{C}$. Serial dilutions of cortisol were, depending on the experiment, prepared in LuriaBertani broth (LB, Sigma-Aldrich NV/SA) or in the corresponding cell culture medium.

\section{Bacterial strains and growth conditions}

Salmonella Typhimurium strain 112910a, isolated from a pig stool sample and characterized previously by Boyen et al., was used as the wild type strain in which the spontaneous nalidixic acid resistant derivative strain $\left(\mathrm{WT}_{\text {nal }}\right)$ was constructed [17]. For fluorescence microscopy, Salmonella Typhimurium strain 112910a carrying the pFPV25.1 plasmid expressing green fluorescent protein (GFP) under the constitutive promoter of rps $M$ was used $[17,18]$.

Unless otherwise stated, the bacteria were generally grown overnight (16 to $20 \mathrm{~h}$ ) as a stationary phase culture with aeration at $37^{\circ} \mathrm{C}$ in $5 \mathrm{~mL}$ of LB broth. To obtain highly invasive late logarithmic cultures for invasion assays, $2 \mu \mathrm{L}$ of a stationary phase culture were inoculated in $5 \mathrm{~mL} \mathrm{LB}$ broth and grown for $5 \mathrm{~h}$ at $37^{\circ} \mathrm{C}$ without aeration [19].

For the oral inoculation of pigs, the $\mathrm{WT}_{\text {nal }}$ was used to minimize irrelevant bacterial growth when plating tonsillar, lymphoid, intestinal and faecal samples. The bacteria were grown for $16 \mathrm{~h}$ at $37^{\circ} \mathrm{C}$ in $5 \mathrm{~mL} \mathrm{LB}$ broth on a shaker, washed twice in Hank's buffered salt solution (HBSS, Gibco, Life Technologies, Paisley, Scotland) by centrifugation at $2300 \times g$ for $10 \mathrm{~min}$ at $4^{\circ} \mathrm{C}$ and finally diluted in HBSS to the appropriate concentration of $10^{7}$ colony forming units (CFU) per $\mathrm{mL}$. The number of viable Salmonella bacteria per $\mathrm{mL}$ inoculum was determined by plating 10-fold dilutions on Brilliant Green agar (BGA, international medical products, Brussels, Belgium) supplemented with $20 \mu \mathrm{g} / \mathrm{mL}$ nalidixic acid (BGA ${ }^{N A L}$, Sigma-Aldrich) for selective growth of the mutant strains.

\section{Cell cultures}

Primary porcine alveolar macrophages (PAM) were isolated by broncho-alveolar washes from lungs of euthanized 3 to 4 week old piglets, obtained from a Salmonella-negative farm, as described previously [20]. The isolated cells were pooled and frozen in liquid nitrogen until further use. Prior to seeding the cells, frozen aliquots of approximately $10^{8}$ cells $/ \mathrm{mL}$ were thawed and washed 3 times in Hank's buffered salt solution with $\mathrm{Ca}^{2+}$ and $\mathrm{Mg}^{2+}(\mathrm{HBSS}+, \mathrm{Gibco})$ with $10 \%(\mathrm{v} / \mathrm{v})$ fetal calf serum (FCS, Hyclone, Cramlington, England) at $4^{\circ} \mathrm{C}$. Finally, these cells were cultured in Roswell Park Memorial Institute medium (RPMI, Gibco) containing 10\% (v/v) FCS, 2 mM L-glutamine (Gibco), 1 mM sodium pyruvate (Gibco), 1\% (v/v) non essential amino acids (NEAA, Gibco), 100 units penicillin per $\mathrm{mL}$ and $100 \mu \mathrm{g}$ streptomycin per $\mathrm{mL}$ (penicillin-streptomycin, Gibco). The porcine macrophage cell line (3D4/31) is derived from PAM and was obtained from Weingartl et al. [21]. These cells were grown in Dulbecco's modified Eagle's medium (DMEM, Gibco) supplemented with 1\% $(\mathrm{v} / \mathrm{v})$ NEAA and $10 \%(\mathrm{v} / \mathrm{v})$ FCS.

The polarized intestinal porcine epithelial (IPEC-J2) cell line is derived from jejunal epithelia isolated from a neonatal piglet and was grown in DMEM supplemented with 47\% (v/v) Ham's F12 medium (Gibco), 5\% (v/v) FCS, 1\% insulin-transferrin-selenium-A supplement (ITS, Gibco), and antibiotics as described above [22,23].

\section{In vivo trials}

All animal experiments were carried out in strict accordance with the recommendations in the European Convention for the Protection of Vertebrate Animals used for Experimental and other Scientific Purposes. The protocols were approved by the ethical committee of the Faculty of Veterinary Medicine, Ghent University (EC 2007/101 and EC 2010/108).

\section{Experimental inoculation of piglets}

A standardized infection model was used to create Salmonella carrier pigs [24]. For this purpose, four-weekold piglets (commercial closed line based on Landrace) were obtained from a serologically negative breeding herd (according to the Belgian Salmonella monitoring program). The Salmonella-free status of the piglets was verified serologically using a commercially available 
Salmonella antibody test kit (IDEXX, Hoofddorp, The Netherlands), and bacteriologically via repeated faecal sampling. The piglets were housed in pairs in separate isolation units at $25^{\circ} \mathrm{C}$ under natural day-night rhythm with ad libitum access to feed and water. Seven days after they arrived, the piglets were orally inoculated with $2 \mathrm{~mL}$ HBSS containing $10^{7} \mathrm{CFU}$ of $\mathrm{WT}_{\text {nal }}$ per $\mathrm{mL}$.

In a first in vivo trial (EC 2007/101), we investigated the effect of different types of stress on the recrudescence of Salmonella Typhimurium by pigs. In a second in vivo trial, (EC 2010/108), we injected pigs intramuscularly with $2 \mathrm{mg}$ dexamethasone per $\mathrm{kg}$ body weight to test our hypothesis that corticosteroids induce the recrudescence of Salmonella Typhimurium in pigs.

\section{Effect of different types of stress on the Salmonella}

\section{Typhimurium load in carrier pigs}

At day 23 post inoculation (pi), pigs were submitted to either social stress $(n=12)$ or feed withdrawal stress $(n$ $=6$ ), mimicking the transport and starvation period before slaughter, respectively. The remaining six pigs were not stressed and served as a negative control group. To induce social stress, the piglets were mixed for $24 \mathrm{~h}$. One piglet was removed from its pen and transferred to another pen, which already contained 2 piglets. This was done in triplicate, so finally there were three groups of 3 piglets per pen (overcrowding) and three groups of 1 piglet per pen (isolation). To mimic feed withdrawal stress, three groups of 2 piglets per pen were not fed for $24 \mathrm{~h}$. After the stress period, the animals were euthanized. Blood samples were taken of all pigs at the same time and the serum cortisol concentrations were determined in twofold via a commercially available enzyme-linked immunosorbent assay (ELISA, Neogen, Lansing, USA), according to the manufacterer's instructions. Furthermore, samples of tonsils, ileocaecal lymph nodes, ileum, caecum, colon and contents of ileum, caecum and colon were collected for bacteriological analysis to determine the number of Salmonella bacteria, with a detection limit of $50 \mathrm{CFU}$ per gram tissue or contents.

\section{Effect of dexamethasone on the Salmonella Typhimurium load in carrier pigs}

The animals $(n=18)$ were housed and inoculated as described above to create Salmonella carrier pigs [17]. At day 42 pi, pigs were intramuscularly injected with either dexamethasone (Kela laboratoria, Hoogstraten, Belgium) $(n=9)$ or HBSS $(n=9)$. Since cortisol has a short half-life of 1 to $2 \mathrm{~h}$ [25], we used dexamethasone, which is a long-acting glucocorticoid with a half-life of

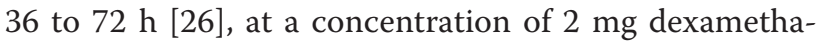
sone per $\mathrm{kg}$ body weight. Pigs are remarkably resistant to dexamethasone-mediated immunosuppression at the dose used [27]. At $24 \mathrm{~h}$ after dexamethasone injection, the animals were euthanized and samples of tonsils, ileocaecal lymph nodes, ileum, caecum, colon and contents of ileum, caecum and colon were collected for bacteriological analysis, with a detection limit of $83 \mathrm{CFU}$ per gram tissue or contents.

\section{Bacteriological analysis}

All tissues and samples were weighed and 10\% (w/v) suspensions were prepared in buffered peptone water (BPW, Oxoid, Basingstoke, United Kingdom). The samples were homogenized with a Colworth stomacher 400 (Seward and House, London, United Kingdom) and the number of Salmonella bacteria was determined by plating 10-fold dilutions on $\mathrm{BGA}^{\mathrm{NAL}}$ plates. These were incubated for $16 \mathrm{~h}$ at $37^{\circ} \mathrm{C}$. The samples were preenriched for $16 \mathrm{~h}$ in $\mathrm{BPW}$ at $37^{\circ} \mathrm{C}$ and, if negative at direct plating, enriched for $16 \mathrm{~h}$ at $37^{\circ} \mathrm{C}$ in tetrathionate broth (Merck KGaA, Darmstadt, Germany) and plated again on $\mathrm{BGA}^{\mathrm{NAL}}$. Samples that were negative after direct plating but positive after enrichment were presumed to contain 50 or $83 \mathrm{CFU}$ per gram tissue or contents (detection limit for direct plating). Samples that remained negative after enrichment were presumed to contain less than 50 or $83 \mathrm{CFU}$ per gram tissue or contents and were assigned value " 1 " prior to log transformation. Subsequently, the number of CFU for all samples derived from all piglets was converted logarithmically prior to calculation of the average differences between the $\log _{10}$ values of the different groups and prior to statistical analysis.

\section{The effects of cortisol and dexamethasone on host- pathogen interactions of Salmonella Typhimurium with porcine host cells}

To examine whether the ability of Salmonella Typhimurium to invade and proliferate in primary porcine alveolar macrophages (PAM) and IPEC-J2 cells was altered after exposure of these cells to cortisol, invasion and intracellular survival assays were performed. For the invasion assays, PAM and IPEC-J2 cells were seeded in 24-well plates at a density of approximately $5 \times 10^{5}$ and $10^{5}$ cells per well, respectively. PAM were allowed to attach for $2 \mathrm{~h}$ and IPEC-J2 cells were allowed to grow for $24 \mathrm{~h}$. Subsequently, the cells were exposed to different concentrations of cortisol ranging from 0.001 to 100 $\mu \mathrm{M}$. After $24 \mathrm{~h}$, the invasion assay was performed as described by Boyen et al. [24]. Briefly, Salmonella was inoculated into the wells at a multiplicity of infection (MOI) of 10:1. To synchronize the infection, the inoculated multiwell plates were centrifuged at $365 \times g$ for 10 min and incubated for $30 \mathrm{~min}$ at $37^{\circ} \mathrm{C}$ under $5 \% \mathrm{CO}_{2}$. Subsequently, the cells were washed 3 times with HBSS + and fresh medium supplemented with $100 \mu \mathrm{g} / \mathrm{mL}$ gentamicin (Gibco) was added. After $1 \mathrm{~h}$ incubation, the PAM and IPEC-J2 cells were washed 3 times and lysed for $10 \mathrm{~min}$ with $1 \%(\mathrm{v} / \mathrm{v})$ Triton X-100 (Sigma-Aldrich) 
or $0.2 \%(\mathrm{w} / \mathrm{v})$ sodium deoxycholate (Sigma-Aldrich), respectively, and 10-fold dilutions were plated on BGA plates.

To assess intracellular proliferation, cells were seeded and inoculated with Salmonella Typhimurium, but the medium containing $100 \mu \mathrm{g} / \mathrm{mL}$ gentamicin was replaced after $1 \mathrm{~h}$ incubation with fresh medium containing 20 $\mu \mathrm{g} / \mathrm{mL}$ gentamicin, with or without cortisol or dexamethasone ranging from 0.001 to $100 \mu \mathrm{M}$. The number of viable bacteria was assessed $24 \mathrm{~h}$ after infection. To examine whether cortisol could also increase the intracellular proliferation of Salmonella Typhimurium in a macrophage cell line, the intracellular proliferation assay was repeated in the 3D14/31 cell line.

To determine whether the observed effect was cortisol specific, invasion and proliferation assays were performed also after exposure of PAM to epinephrine, norepinephrine or dopamine at concentrations ranging from 5 to $50 \mu \mathrm{M}$ to reflect experiments previously performed by others [28].

To visualize the effect of cortisol on the intracellular proliferation of Salmonella bacteria, PAM were seeded in sterile Lab-tek ${ }^{\circledR}$ chambered coverglasses (VWR, Leuven, Belgium), inoculated with GFP-producing Salmonella at a multiplicity of infection of $2: 1$, as described by Boyen et al. [24], and exposed to cortisol at a high physiological stress concentration of $1 \mu \mathrm{M}$ [29] in cell medium or to cell medium only. After $24 \mathrm{~h}$ at $37^{\circ} \mathrm{C}$, cells were washed three times to remove unbound bacteria and cellTrace ${ }^{\mathrm{TM}}$ calcein red-orange (Molecular Probes Europe, Leiden, The Netherlands) was added for $30 \mathrm{~min}$ at $37^{\circ} \mathrm{C}$. Afterwards, cells were washed three times and fluorescence microscopy was carried out. Per experiment the number of cell associated bacteria was determined in 100 macrophages and the average number of cell associated bacteria was calculated from four independent experiments.

The effect of cortisol on the viability of porcine host cells It is possible that cortisol affects the toxicity of Salmonella Typhimurium for host cells, resulting in an increased or reduced cell death. Therefore, the cytotoxic effect of cortisol on uninfected and infected PAM and IPEC-J2 cells was determined using the neutral red uptake assay. For this purpose, PAM were seeded in a 96-well microplate at a density of approximately $2 \times 10^{5}$ cells per well and were allowed to attach for $2 \mathrm{~h}$. The IPEC-J2 cells were seeded and allowed to grow for $24 \mathrm{~h}$ in a 96-well microplate at a density of approximately 2 $\times 10^{4}$ cells per well. As earlier, uninfected and infected cells with Salmonella Typhimurium were treated with medium whether or not supplemented with cortisol concentrations ranging from 0.001 to $100 \mu \mathrm{M}$ for $24 \mathrm{~h}$. To assess cytotoxicity, $150 \mu \mathrm{L}$ of freshly prepared neutral red solution $(33 \mu \mathrm{g} / \mathrm{mL}$ in DMEM without phenol red) prewarmed to $37^{\circ} \mathrm{C}$ was added to each well and the plate was incubated at $37^{\circ} \mathrm{C}$ for an additional $2 \mathrm{~h}$. The cells were then washed two times with HBSS+ and $150 \mu \mathrm{L}$ of extracting solution ethanol/Milli-Q water/ acetic acid, 50/49/1 (v/v/v), was added in each well. The plate was shaken for $10 \mathrm{~min}$. The absorbance was determined at $540 \mathrm{~nm}$ using a microplate ELISA reader (Multiscan MS, Thermo Labsystems, Helsinki, Finland). The percentage of viable cells was calculated using the following formula:

$$
\% \text { cytotoxicity }=100 \times((a-b) /(c-b))
$$

In this formula $\mathrm{a}=\mathrm{OD}_{540}$ derived from the wells incubated with cortisol, $\mathrm{b}=\mathrm{OD}_{540}$ derived from blank wells, $\mathrm{c}=\mathrm{OD}_{540}$ derived from untreated control wells.

\section{Effect of cortisol on the growth and gene expression of Salmonella Typhimurium}

Effect of cortisol on the growth of Salmonella Typhimurium It is possible that cortisol directly increases the growth of Salmonella Typhimurium. Therefore, we examined the effect of cortisol concentrations $(1 \mathrm{nM}, 100 \mathrm{nM}, 1$ $\mu \mathrm{M}$ and $100 \mu \mathrm{M})$ on the growth of Salmonella Typhimurium, during $24 \mathrm{~h}$. For this purpose, Salmonella Typhimurium was grown in LB broth or DMEM medium with or without cortisol. The number of CFU per $\mathrm{mL}$ was determined at different time points $(t=0,2.5$, $5,7.5$ and $24 \mathrm{~h}$ ) by titration of 10 -fold dilutions of the bacterial suspensions on BGA. After incubation for $24 \mathrm{~h}$ at $37^{\circ} \mathrm{C}$, the number of colonies was determined.

\section{Effect of cortisol on the gene expression of Salmonella} Typhimurium

A direct effect of cortisol on the pathogenicity of Salmonella Typhimurium could explain the increased intracellular proliferation in macrophages. Therefore, a microarray analysis was conducted to investigate the effect of cortisol on the gene expression of the bacterium.

RNA was isolated from Salmonella Typhimurium at logarithmic and stationary growth phase $\left(2.00 \mathrm{OD}_{600 \mathrm{~nm}}\right.$ units) in the presence or absence of $1 \mu \mathrm{M}$ cortisol, for 5 and $16 \mathrm{~h}$ respectively [19]. This was done according to procedures described on the IFR microarray web site [30]. The quantity and purity of the isolated RNA was determined using a Nanodrop spectrophotometer and Experion RNA StdSens Analysis kit (Biorad).

Triple biological replicates were performed for each experiment, RNA labeled and hybridized to Salmonella Typhimurium SALSA2 microarrays, consisting of 5080 ORFs, according to protocols described on the IFR microarray web site [30]. Following washing and scanning of the hybridized microarrays, the expression data 
was processed and statistically filtered. All transcriptomic data was normalized to that of the wild-type strain. A Benjamini and Hochberg multiple testing correction was then applied to adjust individual $P$-values so that only data with a false discovery rate of 0.05 and $a \geq$ 1.5 -fold change in the expression level was retained.

The microarray data discussed in this publication are MIAME compliant and have been deposited in NCBI's Gene Expression Omnibus [31] and are accessible through GEO Series accession number GSE30923 [32].

\section{Statistical analysis}

All in vitro experiments were conducted in triplicate with 3 repeats per experiment, unless otherwise stated. All statistical analyses were performed using SPSS version 17 (SPSS Inc., Chicago, IL, USA). Normally distributed data were analyzed using unpaired Student's $t$-test or one-way ANOVA to address the significance of difference between mean values with significance set at $p \leq$ 0.05 . Bonferroni as post hoc test was used when equal variances were assessed. If equal variances were not assessed, the data were analyzed using Dunnett's T3 test. Not normally distributed data were analyzed using the non parametric Kruskal-Wallis analysis, followed by Mann-Whitney U test.

\section{Results}

Feed withdrawal results in increased numbers of Salmonella Typhimurium bacteria in the gut of pigs and elevated blood cortisol levels

Carrier pigs subjected to feed withdrawal, $24 \mathrm{~h}$ before euthanasia, showed elevated numbers of Salmonella Typhimurium per gram in their bowel contents and organs in comparison to the control group (Figure 1). This increase was significant in the ileum $(p \leq 0.001)$, ileum contents $(p=0.022)$ and colon $(p=0.014)$. The social stress groups (overcrowding and isolation) showed no significant differences in comparison to the control group.

Pigs that were subjected to feed withdrawal ( $p=$ $0.004)$ and overcrowding $(p=0.001)$ showed significantly elevated serum cortisol levels compared to the control group that had a mean cortisol concentration \pm standard deviation of $48.65 \pm 4.67 \mathrm{nM}$. Pigs that were starved 24 hours before euthanasia had the highest mean serum cortisol level \pm standard deviation of 66.88 $\pm 6.72 \mathrm{nM}$. Pigs that were housed per 3 (overcrowding) and housed separately (isolation) at $24 \mathrm{~h}$ before euthanasia, had a mean cortisol concentration \pm standard deviation of $59.26 \pm 3.47 \mathrm{nM}$ and $53.66 \pm 2.06 \mathrm{nM}$, respectively.

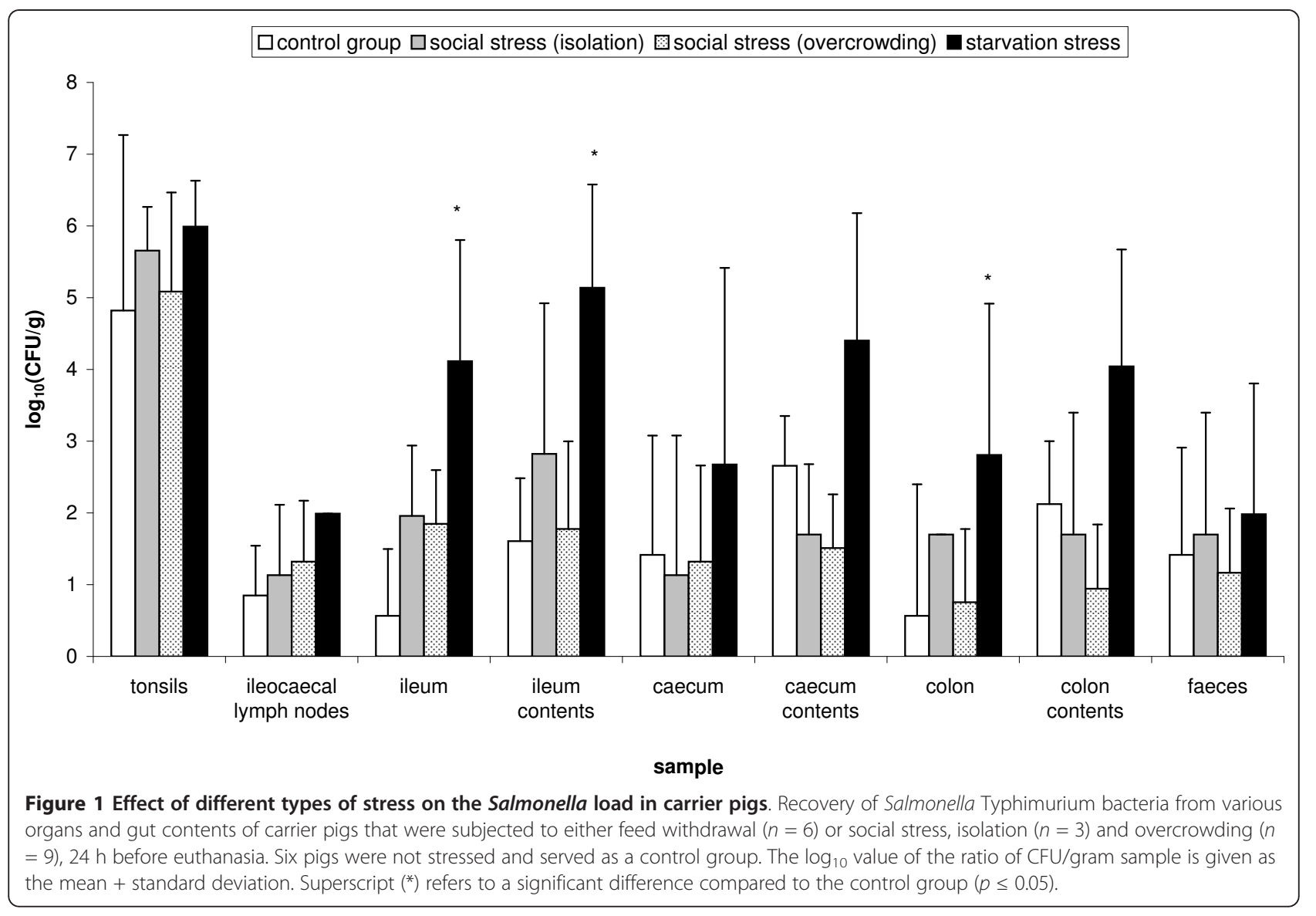


Dexamethasone increases the number of Salmonella Typhimurium bacteria in the gut of carrier pigs Carrier pigs that were intramuscularly injected with 2 mg dexamethasone per $\mathrm{kg}$ body weight, $24 \mathrm{~h}$ before euthanasia, showed elevated numbers of Salmonella Typhimurium in their gut tissues and contents in comparison to the control group that was intramuscularly injected with HBSS (Figure 2). This increase was significant in the ileum $(p=0.018)$, caecum $(p=0.014)$ and colon $(p=0.003)$.

Cortisol and dexamethasone, but not catecholamines, promote the intracellular proliferation of Salmonella Typhimurium in primary porcine macrophages but not in 3D4/31 and IPEC-J2 cells

The results of the intracellular survival assay of Salmonella Typhimurium in PAM with or without exposure to cortisol or dexamethasone are summarized in Figure 3. Exposure to concentrations (> $100 \mathrm{nM}$ ) of cortisol or dexamethasone for $24 \mathrm{~h}$ led to a significant dose-dependent increase of the number of intracellular Salmonella Typhimurium bacteria compared to non-treated PAM.

Cortisol concentrations ranging from 0.001 to $100 \mu \mathrm{M}$ did neither affect the intracellular proliferation of
Salmonella Typhimurium in IPEC-J2 and 3D4/31 cells (Additional file 1), nor the invasion in PAM and IPECJ2 cells (Additional file 2).

The enhanced intracellular proliferation of Salmonella Typhimurium in PAM exposed to a high physiological stress concentration of $1 \mu \mathrm{M}$ cortisol [29] was confirmed in a proliferation assay with GFP-Salmonella. No difference was seen in the mean number of macrophages containing GFP-Salmonella \pm standard error of the mean, after exposure to $1 \mu \mathrm{M}$ cortisol for $24 \mathrm{~h}$ in comparison to untreated PAM $(41.0 \pm 0.53$ versus $40.5 \pm 0.59$ percentage Salmonella positive macrophages, respectively). However, the proliferation rate of intracellular bacteria that were exposed to 1 $\mu \mathrm{M}$ cortisol for $24 \mathrm{~h}$ was significantly $(p=0.001)$ increased in comparison with the control PAM, resulting in a higher mean bacterial count \pm standard error of the mean $(3.1 \pm 0.14$ versus $2.0 \pm 0.07$ bacteria per macrophage, respectively).

Epinephrine, norepinephrine and dopamine at a concentration of $1 \mu \mathrm{M}$ did neither affect the invasion nor the intracellular proliferation of Salmonella Typhimurium in PAM (Additional file 3) and IPEC-J2 cells (Additional file 4).

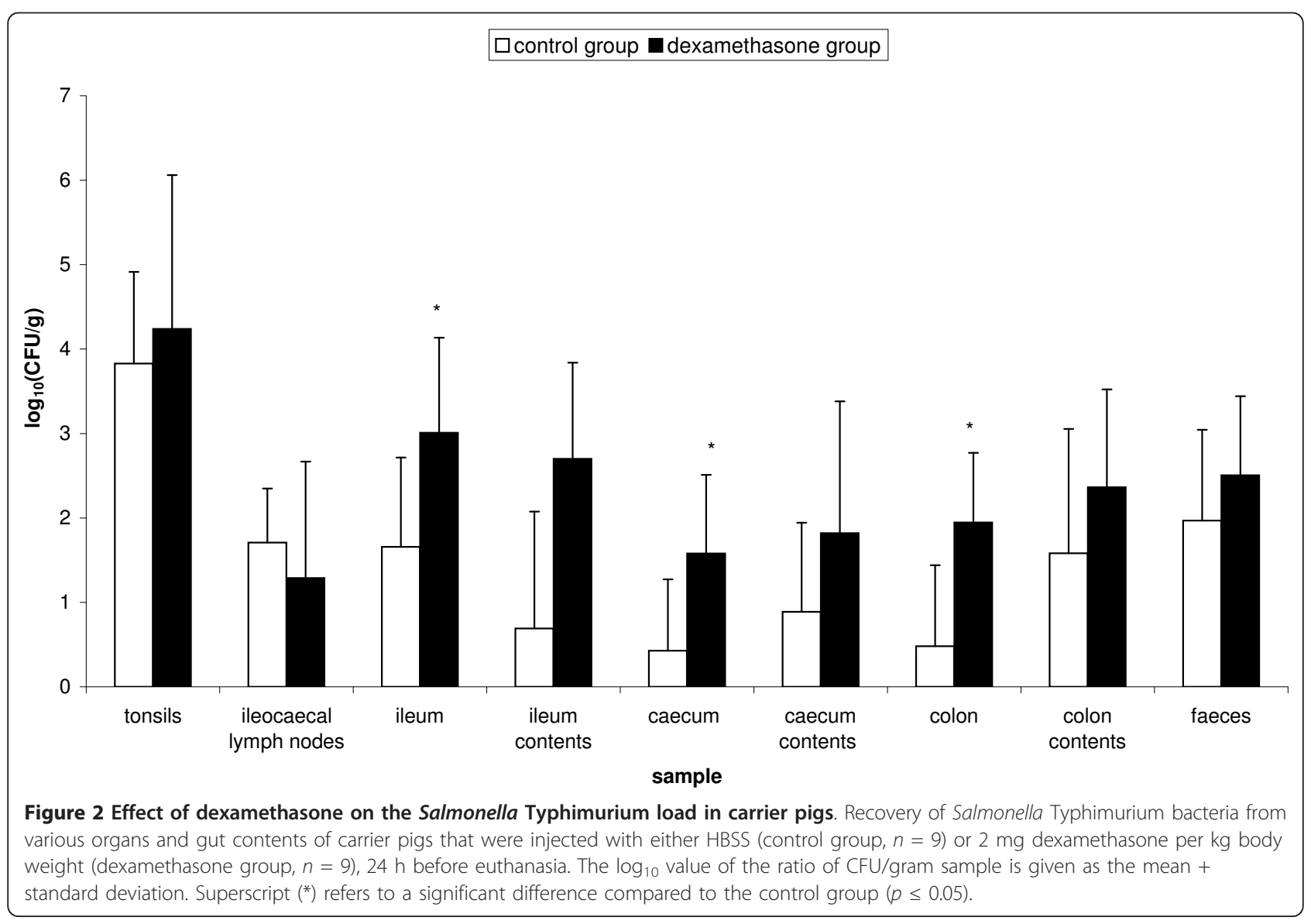




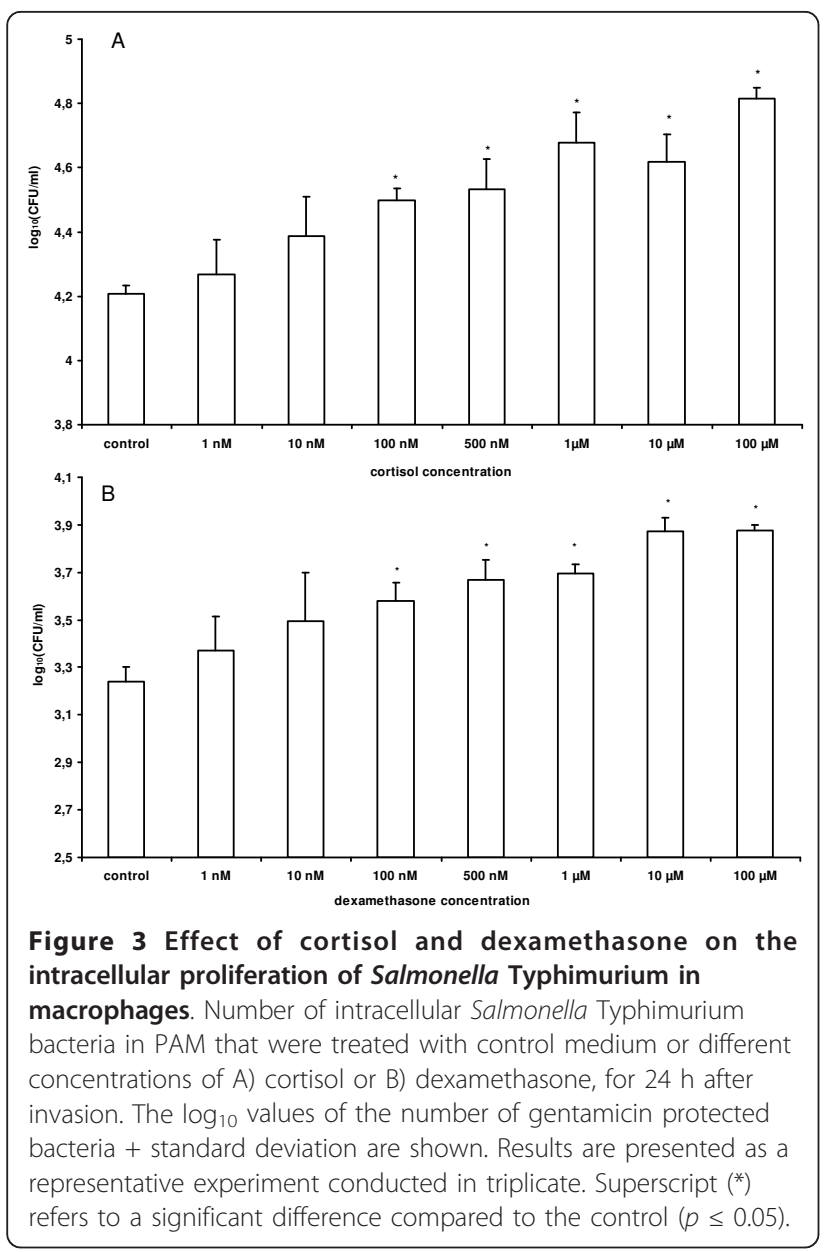

Cortisol does not affect the viability of primary porcine macrophages and intestinal epithelial cells and it does not directly affect Salmonella cytotoxicity, growth and gene expression

Cortisol concentrations ranging from 0.001 to $100 \mu \mathrm{M}$ did neither affect the viability of PAM and IPEC-J2 cells, nor the cytotoxicity of Salmonella Typhimurium for these cells (Figure 4). Furthermore, we showed that cortisol did not affect the growth of Salmonella Typhimurium in LB and DMEM medium (Additional file 5) and transcriptomic analysis revealed that exposure of stationary and logarithmic phase cultures of Salmonella Typhimurium to cortisol at a high physiological stress concentration of $1 \mu \mathrm{M}$ [29], did not significantly affect gene expression levels compared to the untreated strain in LB medium (GSE30923).

\section{Discussion}

Conflicting results have been published concerning the effect of different stressors on the shedding of Salmonella Typhimurium in pigs [33-38]. However, our findings elucidate that a natural stress stimulus like feed
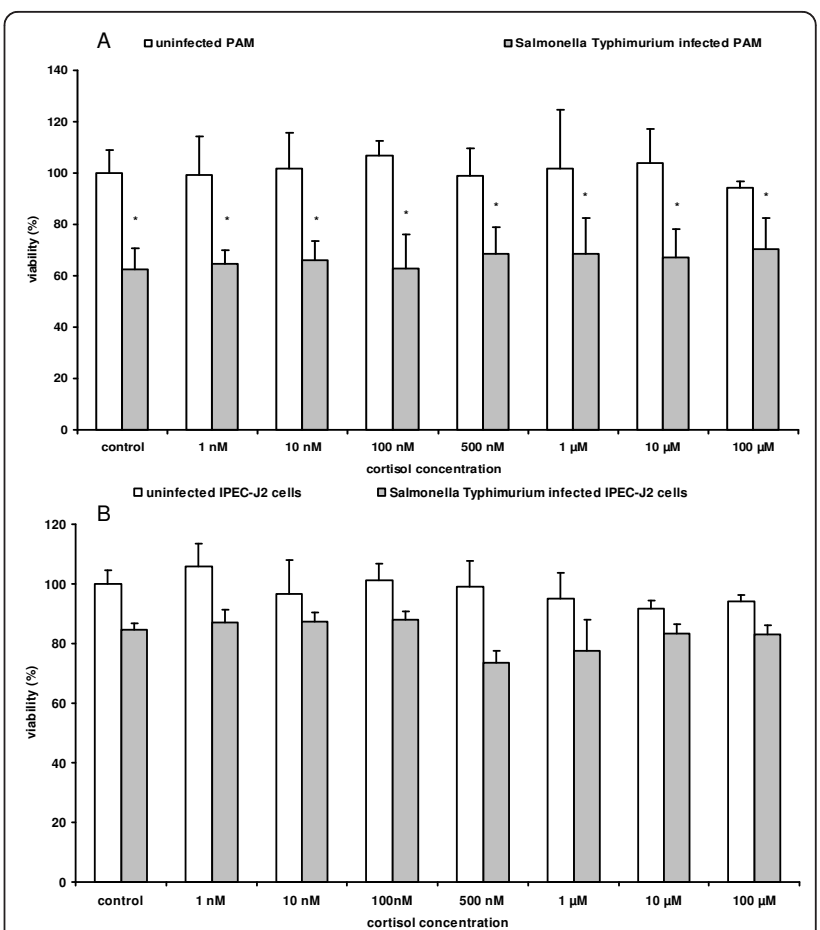

Figure 4 Effect of cortisol on the viability of Salmonella infected and uninfected macrophages and IPEC-J2 cells.

Percentage viability (\%) of Salmonella Typhimurium infected and uninfected (A) PAM and (B) IPEC-J2 cells, exposed to different concentrations of cortisol (0.001-100 $\mu \mathrm{M})$. Twenty-four hours after incubation with cortisol, the cytotoxic effect was determined by neutral red assay. Results represent the means of three independent experiments conducted in triplicate and their standard deviation. Superscript $\left.{ }^{*}\right)$ refers to a significant difference compared to control uninfected IPEC-J2 cells $(p \leq 0.05)$.

withdrawal causes recrudescence of a Salmonella Typhimurium infection in carrier pigs. Feed withdrawal before transport to the slaughterhouse is a common practice to reduce the risk of carcass and environmental contamination because a decrease of the gastrointestinal tract weight results in a lower risk of lacerations during evisceration [39]. However, we showed that feed withdrawal practices could result in an increased risk of contamination. Martín-Peláez et al. hypothesized that the increased faecal excretion of Salmonella Typhimurium after feed withdrawal could be the result of a lower short-chain fatty acids concentration, an increased $\mathrm{pH}$ or an increased number of lactic acid bacteria such as lactobacilli [34].

Until now, the mechanism of stress related recrudescence of Salmonella is not well understood and the investigation of this phenomenon is hindered by the lack of appropriate animal models [40,41]. The higher Salmonella Typhimurium numbers in pigs subjected to feed withdrawal stress, suggest that this model is a valuable tool for the study of stress related Salmonella 
recrudescence. We hypothesized that cortisol plays a role in the stress related recrudescence of Salmonella Typhimurium by pigs. During a stress reaction, the sympathetic nervous system and hypothalamic-pituitaryadrenal axis become activated, resulting in the release of catecholamines and glucocorticoids, respectively [15]. These stress hormones can affect the host immune response, but the pathogenesis of an infection can also be altered by direct effects of these stress mediators on the bacteria [13].

We showed that social stress and starvation result in elevated serum cortisol levels. Starvation can result in hypoglycaemia, which causes an increased secretion of cortisol to stimulate the gluconeogenesis [42]. Müller et al. showed that a starvation period up to 5 days in miniature pigs, results in a slight, but insignificant elevation of plasma cortisol levels [43]. Therefore, the elevated serum cortisol levels, seen in the carrier pigs that were subjected to feed withdrawal is probably the result of a combination between the feed withdrawal itself and the stress that is involved.

We revealed that a short-term treatment of carrier pigs with a high dose of dexamethasone results in the recrudescence of Salmonella Typhimurium. This confirms that the release of corticosteroids in the bloodstream itself could alter the outcome of a Salmonella Typhimurium infection in pigs, resulting in recrudescence of the infection. Smyth et al. showed that long-term treatment of mice with dexamethasone promotes a dose-dependent increase in Salmonella Typhimurium growth within mouse livers and spleens [44]. The increased numbers of bacteria described by Smyth et al. are probably the result of the immunosuppressive activity of glucocorticoids. Pigs are remarkably resistant to immunosuppression of dexamethasone, even at a high dose of $2 \mathrm{mg} / \mathrm{kg}$ body weight [27,45-47]. Therefore, the dexamethasone induced recrudescense of Salmonella Typhimurium in pigs is probably not the direct consequence of the immunosuppressive activity of dexamethasone.

We also demonstrated that this glucocorticoid mediated effect was not the result of a direct effect on the bacterium. Earlier research has shown that norepinephrine in vitro promotes the growth and the motility of Salmonella enterica $[48,49]$. However, we provide evidence that cortisol does not cause an increase in growth in LB and DMEM medium, or any significant changes in the gene expression of Salmonella Typhimurium when grown in a complex medium, at a physiological stress concentration of $1 \mu \mathrm{M}$ [29]. In contrast to the absence of a direct effect on the bacterium, we showed that cortisol and dexamethasone promote intracellular proliferation of Salmonella Typhimurium in porcine macrophages, in a dose-dependent manner at concentrations $(0.1$ to $100 \mu \mathrm{M})$ that do not exert a notable effect on cell viability. Nevertheless, this increased survival was not observed 3D4/31 and IPEC-J2 cells. Although Salmonella is an extensively studied bacterium, still many questions remain about the intracellular environment of Salmonella within different host cells. After invasion, Salmonella resides within Salmonella containing vacuoles (SCV) which serves a unique intracellular compartment where it resides and eventually replicates. Maturation of the SCV has been studied in different cell types and these studies indicate that the SCV biogenesis may not be generalized [50]. Possibly, cortisol affects the SCV biogenesis in primary macrophages and not in other cell types, which results in an increased survival of the bacterium in these primary macrophages.

Although we showed that catecholamines did neither affect the intracellular proliferation nor the invasion of Salmonella Typhimurium in primary macrophages and IPEC-J2 cells, catecholamines have been shown to promote the growth and motility of Salmonella [48,49,51]. Concentrations of the catecholamines were not determined in the in vivo trial since they have a half-life of approximately $3 \mathrm{~min}$ and because their serum levels change in matter of seconds [52,53]. However, it is commonly known that a stress reaction also results in the release of catecholamines. Recently, Pullinger et al. demonstrated that the release of norepinephrine in pigs by administration of 6-hydroxydopamine, enhances the faecal extretion of Salmonella Typhimurium [54]. Therefore, it is possible that catecholamines and glucocorticoids act in a synergistic way to cause a sudden increase of Salmonella Typhimurium shedding in stressed animals. Since stress is very common in food producing animals and since these stress hormones and derivatives are frequently used in human and animal medicine, their effects need further examination [55,56]. The elucidation of the mechanisms through which stress and its hormones alter the susceptibility to an infection could help to improve the prevention and treatment of Salmonella Typhimurium infections in pigs, and as a consequence help to reduce the number of cases of human salmonellosis.

In conclusion, we showed that the glucocorticoid cortisol is involved in a stress induced recrudescence of Salmonella Typhimurium in carrier pigs. In addition to this, we pointed out that cortisol promotes the intracellular proliferation of Salmonella Typhimurium in porcine macrophages which is caused by an indirect effect through the cell.

\section{Additional material}

Additional file 1: Effect of cortisol on the intracellular proliferation of Salmonella Typhimurium in IPEC-J2 and 3D4/31 cells. Number of intracellular Salmonella Typhimurium bacteria in (A) IPEC-J2 cells and (B) 
$3 \mathrm{D} 4 / 31$ cells, that were treated with control medium or cortisol $(0.001$ $\mu \mathrm{M}-100 \mu \mathrm{M})$, for $24 \mathrm{~h}$ after invasion. The $\log _{10}$ values of the number of gentamicin protected bacteria + standard deviation are given. Results are presented as a representative experiment conducted in triplicate.

\section{Additional file 2: Effect of cortisol on the invasion of Salmonella} Typhimurium in macrophages and IPEC-J2 cells. The invasiveness of Salmonella Typhimurium in (A) PAM and (B) IPEC-J2 cells, whether or not exposed to cortisol (0.001-100 $\mu \mathrm{M}$ ) is shown. The $\log _{10}$ values of the number of gentamicin protected bacteria + standard deviation are given. Results are presented as a representative experiment conducted in triplicate.

Additional file 3: Effects of catecholamines on the invasion and intracellular proliferation of Salmonella Typhimurium in macrophages. The invasiveness (A) and the survival (B), $24 \mathrm{~h}$ after invasion, of Salmonella Typhimurium in PAM whether or not exposed to epinephrine, norepinephrine or dopamine $(5-50 \mu \mathrm{M})$ is shown. The $\log _{10}$ values of the number of gentamicin protected bacteria + standard deviation are given. Results are presented as a representative experiment conducted in sixfold.

Additional file 4: Effect of catecholamines on the invasion and intracellular proliferation of Salmonella Typhimurium in IPEC-J2 cells. The invasiveness (A) and the survival (B), $24 \mathrm{~h}$ after invasion, of Salmonella Typhimurium in IPEC-J2 cells whether or not exposed to epinephrine, norepinephrine or dopamine $(5-50 \mu \mathrm{M})$ is shown. The $\log _{10}$ values of the number of gentamicin protected bacteria + standard deviation are given. Results are presented as a representative experiment conducted in sixfold.

Additional file 5: Effect of cortisol on the growth of Salmonella Typhimurium. The $\log _{10}$ values of the $\mathrm{CFU} / \mathrm{mL}+$ standard deviation are given at different time points $(t=0,2.5,5,7.5,24 \mathrm{~h})$. Salmonella Typhimurium growth was examined in (A) LB and (B) DMEM medium, with or without cortisol (0.001-100 $\mu \mathrm{M})$. Results are presented as a representative experiment conducted in triplicate.

\section{Acknowledgements}

This work was supported by the Federal Public Service for Health, Food chain safety and Environment (FOD), Brussels, Belgium: project code RF6181. The IPEC-J2 cell line was a kind gift of Dr Schierack, Institut für Mikrobiologie und Tierseuchen, Berlin, Germany. The 3D4/31 cell line was a kind gift of Dr Weingartl, Department of Medical Microbiology, Faculty of Medicine, University of Manitoba, Canada. The technical assistance of Nathalie Van Rysselberghe, Rosalie Devloo and Anja Van den Bussche is greatly appreciated.

\section{Author details}

'Department of Pathology, Bacteriology and Avian Diseases, Faculty of Veterinary Medicine, Ghent University, Salisburylaan 133, 9820 Merelbeke, Belgium. ${ }^{2}$ Department of Pharmacology, Toxicology and Biochemistry, Faculty of Veterinary Medicine, Ghent University, Salisburylaan 133, 9820 Merelbeke, Belgium. ${ }^{3}$ Department of Foodborne Bacterial Pathogens, Institute of Food Research, Norwich Research Park, Colney Lane, Norwich NR4, UK.

\section{Authors' contributions}

$\mathrm{EV}, \mathrm{AT}$ and NS performed the microarray analysis. EV, AVP, KVD and BL performed the animal experiments. EV, FB, FH, SC and FP conceived the study, participated in its design and coordination. EV, FH and FP co-drafted the manuscript. All authors read and approved the final manuscript.

\section{Competing interests}

The authors declare that they have no competing interests.

Received: 27 September 2011 Accepted: 7 December 2011 Published: 7 December 2011

\section{References}

1. Rostagno $\mathrm{MH}$ : Can stress in farm animals increase food safety risk? Foodborne Pathog Dis 2009, 6:767-776.

2. Burkholder KM, Thompson KL, Einstein ME, Applegate TJ, Patterson JA: Influence of stressors on normal intestinal microbiota, intestinal morphology, and susceptibility to Salmonella enteritidis colonization in broilers. Poult Sci 2008, 87:1734-1741.

3. Alban L, Stege H, Dahl J: The new classification system for slaughter-pig herds in the Danish Salmonella surveillance-and-control program. Prev Vet Med 2002, 53:133-146.

4. Berends BR, Urlings HA, Snijders JM, Van Knapen F: Identification and quantification of risk factors in animal management and transport regarding Salmonella spp. in pigs. Int J Food Microbiol 1996, 30:37-53.

5. Berends BR, Van Knapen F, Mossel DA, Burt SA, Snijders JM: Impact on human health of Salmonella spp. on pork in The Netherlands and the anticipated effects of some currently proposed control strategies. Int J Food Microbiol 1998, 44:219-229.

6. Snary EL, Munday DK, Arnold ME, Cook AJ: Zoonoses action plan Salmonella monitoring programme: an investigation of the sampling protocol. J Food Prot 2010, 73:488-494.

7. Boyen F, Haesebrouck F, Maes D, Van Immerseel F, Ducatelle R, Pasmans F: Non-typhoidal Salmonella infections in pigs: a closer look at epidemiology, pathogenesis and control. Vet Microbiol 2008, 130:1-19.

8. Wong $D$, Hald $T$, van der Wolf $P$, Swanenburg M: Epidemiology and control measures for Salmonella in pigs and pork. Livest Proc Sci 2002, 76:215-222.

9. Freestone PP, Lyte M: Microbial endocrinology: experimental design issues in the study of interkingdom signalling in infectious disease. Adv Appl Microbiol 2008, 64:75-105.

10. Merlot E, Mounier AM, Prunier A: Endocrine response of gilts to various common stressors: a comparison of indicators and methods of analysis. Physiol Behav 2011, 102:259-265.

11. Muráni E, Ponsuksili S, D'Eath RB, Turner SP, Evans G, Thölking L, Kurt E, Klont $R$, Foury $A$, Mpormède $P$, Wimmers $K$ : Differential mRNA expression of genes in the porcine adrenal gland associated with psychosocial stress. J Mol Endocrinol 2011, 46:165-174.

12. Dhabhar FS: Enhancing versus suppressive effects of stress on immune function: implications for immunoprotection and immunopathology. Neuroimmunomodulation 2009, 16:300-317.

13. Verbrugghe E, Boyen F, Gaastra W, Bekhuis L, Leyman B, Van Parys A, Haesebrouck F, Pasmans F: The complex interplay between stress and bacterial infections in animals. Vet Microbiol

14. Lyte M: Microbial endocrinology and infectious disease in the 21st century. Trends Microbiol 2004, 12:14-20.

15. Freestone PP, Sandrini SM, Haigh RD, Lyte M: Microbial endocrinology: how stress influences susceptibility to infection. Trends Microbiol 2008 16:55-64.

16. Worsaae $\mathrm{H}$, Schmidt M: Plasma cortisol and behaviour in early weaned piglets. Acta Vet Scand 1980, 21:640-657.

17. Boyen F, Pasmans F, Van Immerseel F, Morgan E, Botteldoorn N, Heyndrickx M, Volf J, Favoreel H, Hernalsteens JP, Ducatelle R, Haesebrouck F: A limited role for SsrA/B in persistent Salmonella Typhimurium infections in pigs. Vet Microbiol 2008, 128:364-373.

18. Van Immerseel F, De Buck J, Boyen F, Bohez L, Pasmans F, Volf J, Sevcik M, Rychlik I, Haesebrouck F, Ducatelle R: Medium-chain fatty acids decrease colonization and invasion through hilA suppression shortly after infection of chickens with Salmonella enterica serovar Enteritidis. Appl Environ Microbiol 2004, 70:3582-3587.

19. Lundberg U, Vinatzer U, Berdnik D, von Gabain A, Baccarini M: Growth phase-regulated induction of Salmonella-induced macrophage apoptosis correlates with transient expression of SPI-1 genes. J Bacteriol 1999, 181:3433-3437.

20. Dom P, Haesebrouck F, De Baetselier P: Stimulation and suppression of the oxygenation activity of porcine pulmonary alveolar macrophages by Actinobacillus pleuropneumoniae and its metabolites. Am J Vet Res 1992. 53:1113-1118.

21. Weingartl H, Sabara M, Pasick J, van Moorlehem E, Babiuk L: Continuous porcine cell lines developed from alveolar macrophages - Partial characterization and virus susceptibility. J Virol Methods 2002, 104:203-216. 
22. Rhoads JM, Chen W, Chu P, Berschneider HM, Argenzio RA, Paradiso AM: Lglutamine and L-asparagine stimulate $\mathrm{Na}+-\mathrm{H}+$ exchange in porcine jejunal enterocytes. Am J Physiol 1994, 266:G828-G838.

23. Schierack $P$, Nordhoff $M$, Pollmann M, Weyrauch KD, Amasheh $S$, Lodemann U, Jores J, Tachu B, Kleta S, Blikslager A, Tedin K, Wieler LH: Characterization of a porcine intestinal epithelial cell line for in vitro studies of microbial pathogenesis in swine. Histochem Cell Biol 2006, 125:293-305.

24. Boyen F, Pasmans F, Van Immerseel F, Donné E, Morgan E, Ducatelle R, Haesebrouck F: Porcine in vitro and in vivo models to assess the virulence of Salmonella enterica serovar Typhimurium for pigs. Lab Anim 2009, 43:46-52.

25. Perogamvros I, Aarons L, Miller AG, Trainer PJ, Ray DW: Corticosteroidbinding globulin regulates cortisol pharmacokinetics. Clin Endocrinol (Oxf) 2011, 74:30-36.

26. Shefrin AE, Goldman RD: Use of dexamethasone and prednisone in acute asthma exacerbations in pediatric patients. Can Fam Physician 2009, 55:704-706.

27. Flaming KP, Gogg BL, Roth F, Roth JA: Pigs are relatively resistant to dexamethasone induced immunosuppression. Comp Haematol Int 1994, 4:218-225.

28. Bearson BL, Bearson SMD, Uthe JJ, Dowd SE: Iron regulated genes of Salmonella enterica serovar Typhimurium in response to norepinephrine and the requirement of fepDGC for norepinephrine-enhanced growt. Microbes Infect 2008, 10:807-816.

29. Wei $S, X u H$, Xia D, Zhao R: Curcumin attenuates the effects of transport stress on serum cortisol concentration, hippocampal NO production, and BDNF expression in the pig. Domest Anim Endocrinol 2010, 39:231-239.

30. Thompson A, Shearer N: IFR Microarray Facility.[http://www.ifr.ac.uk/Safety/ microarrays/].

31. Edgar R, Domrachev M, Lash AE: Gene Expression Omnibus: NCBI gene expression and hybridization array data repository. Nucleic Acids Res 2002, 30:207-210.

32. Gene Expression Omnibus. [http://www.ncbi.nlm.nih.gov/geo/query/acc. cgi?acc $=$ GSE30923].

33. Isaacson RE, Firkins LD, Weigel RM, Zuckermann FA, DiPietro JA: Effect of transportation and feed withdrawal on shedding of Salmonella typhimurium among experimentally infected pigs. Am J Vet Res 1999, 60:1155-1158.

34. Martín-Peláez S, Peralta B, Creus E, Dalmau A, Velarde A, Pérez JF, Mateu E, Martín-Orúe SM: Different feed withdrawal times before slaughter influence caecal fermentation and faecal Salmonella shedding in pigs. Vet J 2009, 182:469-473.

35. Nollet N, Houf K, Dewulf J, De Kruif A, De Zutter L, Maes D: Salmonella in sows: a longitudinal study in farrow-to-finish pig herds. Vet Res 2005, 36:645-656.

36. Rostagno $\mathrm{MH}$, Hurd HS, McKean JD: Resting pigs on transport trailers as an intervention strategy to reduce Salmonella enterica prevalence at slaughter. J Food Prot 2005, 68:1720-1723.

37. Scherer K, Szabó I, Rösler U, Appel B, Hensel A, Nöckler K: Time course of infection with Salmonella typhimurium and its influence on fecal shedding, distribution in inner organs, and antibody response in fattening pigs. J Food Prot 2008, 71:699-705.

38. Williams LP, Newell KW: Salmonella excretion in joy-riding pigs. Am J Public Health Nations Health 1970, 60:926-929.

39. Miller M, Carr M, Bawcom D, Ramsey C, Thompson L: Microbiology of pork carcasses from pigs with differing origins and feed withdrawal times. J Food Prot 1997, 60:242-245.

40. Griffin AJ, Li LX, Voedisch S, Pabst O, McSorley SJ: Dissemination of persistent intestinal bacteria via the mesenteric lymph nodes causes typhoid relapse. Infect Immun 2011, 79:1479-1488.

41. Stabel TJ, Fedorka-Cray PJ: Effect of 2-deoxy-d-glucose induced stress on Salmonella choleraesuis shedding and persistence in swine. Res Vet Sci 2004, 76:187-194

42. Guettier JM, Gorden P: Hypoglycemia. Endocrinol Metab Clin North Am 2006, 35:753-766.

43. Müller MJ, Paschen U, Seitz HJ: Starvation-induced ketone body production in the conscious unrestrained miniature pig. J Nutr 1982, 112:1379-1386.
44. Smyth T, Tötemeyer S, Haugland S, Willers C, Peters S, Maskell D, Bryant C: Dexamethasone modulates Salmonella enterica serovar Typhimurium infection in vivo independently of the glucocorticoid-inducible protein annexin-A1. FEMS Immunol Med Microbiol 2008, 54:339-348.

45. Griffin JF: Stress and immunity: a unifying concept. Vet Immunol Immunopathol 1989, 20:263-312.

46. Roth JA, Flaming KP: Model systems to study immunomodulation in domestic food animals. Adv Vet Sci Comp Med 1990, 35:21-41.

47. Saulnier D, Martinod S, Charley B: Immunomodulatory effects in vivo of recombinant porcine interferon gamma on leukocyte functions of immunosuppressed pigs. Ann Rech Vet 1991, 22:1-9.

48. Bearson BL, Bearson SM: The role of the QseC quorum-sensing sensor kinase in colonization and norepinephrine-enhanced motility of Salmonella enterica serovar Typhimurium. Microb Pathog 2008, 44:271-278.

49. Methner U, Rabsch W, Reissbrodt R, Williams PH: Effect of norepinephrine on colonisation and systemic spread of Salmonella enterica in infected animals: role of catecholate siderophore precursors and degradation products. Int J Med Microbiol 2008, 298:429-439.

50. Gorvel JP, Méresse S: Maturation steps of the Salmonella-containing vacuole. Microbes Infect 2001, 3:1299-1303.

51. Toscano MJ, Stabel TJ, Bearson SMD, Bearson BL, Lay DC: Cultivation of Salmonella enterica serovar Typhimurium in a norepinephrine-containing medium alters in vivo tissue prevalence in swine. J Exp Anim Sci 2007, 43:329-338.

52. Whitby L, Axelrod J, Weilmalherbe H: Fate of H3-Norepineprhine in animals. J Pharmacol Exp Ther 1961, 132:193-201.

53. Yamaguchi I, Kopin IJ: Plasma catechomaline and blood pressure responses to sympathetic stimulaion in pithed rats. Am J Physio/ 1979, 237: $\mathrm{H} 305-\mathrm{H} 310$.

54. Pullinger GD, van Diemen PM, Carnell SC, Davies H, Lyte M, Stevens MP: 6hydroxydopamine-mediated release of norepinephrine increases faecal excretion of Salmonella enterica serovar Typhimurium in pigs. Vet Res 2010, 41:68.

55. Behrend EN, Kemppainen RJ: Glucocorticoid therapy. Pharmacology, indications, and complications. Vet Clin North Am Small Anim Pract 1997, 27:187-213.

56. Lowe AD, Campbell KL, Graves T: Glucocorticoids in the cat. Vet Dermatol 2008, 19:340-347.

doi:10.1186/1297-9716-42-118

Cite this article as: Verbrugghe et al:: Stress induced Salmonella Typhimurium recrudescence in pigs coincides with cortisol induced increased intracellular proliferation in macrophages. Veterinary Research 2011 42:118.

\section{Submit your next manuscript to BioMed Central and take full advantage of:}

- Convenient online submission

- Thorough peer review

- No space constraints or color figure charges

- Immediate publication on acceptance

- Inclusion in PubMed, CAS, Scopus and Google Scholar

- Research which is freely available for redistribution

Submit your manuscript at www.biomedcentral.com/submit
C Biomed Central 